\title{
Inter-male aggression in relation to female availability and residence status in corn mice Calomys musculinus
}

\author{
Andrea R. Steinmann • José W. Priotto
}

Received: 16 December 2009 / Accepted: 18 May 2010/Published online: 3 December 2010

(C) Mammal Research Institute, Polish Academy of Sciences, Białowieża, Poland 2010

\begin{abstract}
We conducted an experimental study to test the hypothesis that, at low female availability, males show intrasexual aggressive behaviour and home range owners are more aggressive than home range intruders. Using field dyadic arena test, we carried out 35 male-male trials in four 0.25 ha enclosures, two male-biased (experimental enclosures) and two unbiased (control enclosures). Dyadic encounters were conducted between unrelated and sexually mature males of similar weight and age which established home ranges in the same enclosure at the same trapping session. Each inter-male encounter was performed in the home range of one of the opponents between the home range owner and a home range intruder. When sex ratios were male-biased, intermale amicable behaviour was absent and we found significant rates of inter-male aggressiveness, being home range owners much more aggressive than intruders. In the unbiased enclosures, inter-male encounters resulted mainly in noninteractive or amicable interactions. We found that inter-male aggression varied in relation to female availability being more evident in home range owners.
\end{abstract}

Keywords Aggressive behaviour. Calomys musculinus. Density $\cdot$ Spacing behaviour $\cdot$ Neotropical rodent

Communicated by: Joseph F. Merritt

A. R. Steinmann · J. W. Priotto

Departamento de Ciencias Naturales,

Universidad Nacional de Río Cuarto,

Agencia Postal No. 3,

5800, Río Cuarto, Córdoba, Argentina

A. R. Steinmann · J. W. Priotto $(\bowtie)$

Consejo Nacional de Investigaciones Científicas

y Técnicas (CONICET),

Argentina

URL: http://www.conicet.gov.ar

e-mail: jpriotto@gmail.com

\section{Introduction}

Several studies of rodents at population level have revealed the impact of density and sex ratio on behavioural interactions among individuals (Agrell et al. 1996; Bond and Wolff 1999; Krebs 1978; Moorhouse and Macdonald 2008; Ostfeld 1985; Ostfeld and Klosterman 1990). Within a species, the ultimate determinants causing variation in the pattern and intensity of aggressive behaviour among individuals include ecological and demographic factors. Ecologically, aggression increases with scarcity of resources, and demographically, it increases with population density (Emlen and Oring 1977; Frank and Heske 1992; Knell 2009; Nevo 2007; Pusenius and Viitala 1993; Schradin 2004). Many studies in voles and mice have related the effect of total population density, density of males and density of females with spacing behaviour and aggressiveness (Agrell et al. 1996; Boonstra et al. 1994; Bond and Wolff 1999; Flowerdew 1974; Ims 1987; Knell 2009; Moorhouse and MacDonald 2005, 2008; Pusenius and Viitala 1993; Spritzer et al. 2004, 2006). In promiscuous species, where males provide minimal parental care and do not form long-term pair bonds (Bond and Wolff 1999; Wolff 1985; 1993; Wolff et al. 1994), female aggressiveness is associated with territoriality and reproductive activity. In these species, the limiting resources for spacing behaviour in females are food and space to rear offspring, whereas for males, only oestrous females are important (Frank and Heske 1992; Loughran 2007; Shier and Randall 2004; Steinmann et al. 2009; Wolff 1993). Thus, females attempt to maximize offspring survival, whereas males attempt to mate with as many females as possible (Ims 1987; Wolff and Macdonald 2004). This may cause considerable competition among males for access to females. Nelson (1995a), Agrell et al. (1996) and Bond 
and Wolff (1999) found that a low availability of females could lead to male competition for mates, usually through direct aggressive interactions. Therefore, the two main factors that should limit reproductive success of a male are the number of females to which it has access and the number of male competitors with which it interacts (Nelson 1995a, b; Ostfeld et al. 1993; Ostfeld and Canham 1995; Wolff and Dunlap 2002; Wolff and Macdonald 2004).

Either spacing behaviour or territoriality leads to increase reproductive success by defending a particular area containing critical resources (Bondrup-Nielsen 1986; Davies and Houston 1981; Stamps 1995). A widespread characteristic of territorial behaviour is that residents almost invariably defeat challengers, often with less fighting abilities than the challenger (Beletsky and Orians 1987). The value asymmetry hypothesis is one of the three general hypotheses that have been proposed to explain this circumstance (Krebs 1982; Maynard Smith and Parker 1976; Maynard Smith 1979; Parker and Rubenstein 1981). This hypothesis proposes that residents win as a result of their greater investment and local experience in comparisons with the challengers (Beletsky and Orians 1989). Besides, awareness of food sources (Davies 1981), established boundaries with neighbours (Beletsky and Orians 1987) and reproductive investment (Hatchwell and Davies 1992) are all additional potential factors underlying value asymmetries between owners and intruders (Tobias 1997). Thus, the asymmetry in the value of resources would also affect the aggressive behaviour of individuals.

Calomys musculinus has a promiscuous mating system, and females typically mate with more than one male during each oestrous period (Steinmann et al. 2009). Males have home ranges that are more than twice as large as those of females (500 and $250 \mathrm{~m}^{2}$, respectively, in average), and they fully share them with both sexes (Steinmann et al. 2005). In populations with similar sex ratio females are the territorial sex, whereas males are nonterritorial and show high levels of intrasexual tolerance and amicable behaviours (Steinmann et al. 2009). In previous studies on $C$. musculinus, we found that the absence of adult males or females affects spacing behaviour of males, whereas female spacing behaviour remains unchanged (Steinmann et al 2006a, b). At high number of adult females, C. musculinus males enlarge their home range areas and overlap degree, probably as a mechanism to take access to a greater number of reproductive females (Steinmann et al. 2006a). On the other hand, at low number of adult females, males deeply decrease their home range sizes and the degree of intrasexual home range overlap in almost 50\% (Steinmann et al. 2006b). This spatial avoidance would reflect an increase in competition among males for monopolizing the receptive females (Steinmann et al. 2006b). Studies carried out by Nelson (1995a, b), Ylönen and Viitala (1985) and Bond and
Wolff (1999) support the hypothesis of the importance of female availability as a key resource in determining male space use during the breeding period. Although we have widely studied the use of space in C. musculinus (Steinmann et al. 2005, 2006a, b, 2009), the influence of breeding female availability on aggressive interactions among males has not been experimentally studied until now. Thus, our objective was to test the hypothesis that when females become a limited resource, males change their strategy for monopolizing receptive females. We predict that at low female availability, males show intrasexual aggressive behaviour, and home range owners, which have a greater investment and more local experience in their own home range than challengers, are more aggressive than home range intruders.

\section{Study area}

The study area was located on the Espinal Reservation in the National University of Río Cuarto Campus $\left(33^{\circ} 07^{\prime} \mathrm{S}\right.$, $\left.64^{\circ} 14^{\prime} \mathrm{W}\right)$, Argentina. Phytogeographically, this region corresponds to 'Provincia del Espinal, Distrito del Algarrobo' (Cabrera 1953), which is a low plain (elevation 600-900 m) with vegetation dominated by algarrobo (Prosopis alba, Prosopis nigra), accompanied by quebracho blanco (Aspidosperma quebracho blanco), mistol (Zizyphus mistol) and itin (Portulaca kuntzie). This study was carried out in four 0.25 ha $(62.5 \mathrm{~m} \times 40.0 \mathrm{~m})$ field enclosures made of galvanized iron sheets extending $0.3 \mathrm{~m}$ underground and $0.7 \mathrm{~m}$ above ground. Two enclosures with unbiased sex ratio (controls I and II), and two male-biased enclosures (experimental I and II). The enclosures were situated in a natural pasture interspersed with woody shrubs and herbaceous weedy species, natural habitats of $C$. musculinus.

\section{Material and methods}

The study species, the corn mouse Calomys musculinus

C. musculinus (Cricetidae, Sigmodontinae) is the dominant rodent species of central Argentina, and it was mainly studied due to its role as reservoir of Junin virus, etiological agent of the Argentine hemorragic fever (AHF; de Villafañe and Bonaventura 1987; Mills and Childs 1998). It inhabits Pampean agrarian ecosystems and is found in a variety of habitats including natural pastures, cropfields, road borders, borders between cultivated fields or pastures and railway banks (Busch et al. 2000). C. musculinus populations are characterized by seasonal density changes with low density during winter and peaks during late summer or early autumn (Mills and Childs 1998). C. musculinus is a 
granivorous small mouse $(75 \mathrm{~mm}$ of head body length and $85 \mathrm{~mm}$ of tail length, body mass: $22 \mathrm{~g}$ ) mainly nocturnal, but often diurnal as well (Busch et al. 2000; de Villafañe and Bonaventura 1987; Mills et al. 1992). The reproductive period of this species begins in mid-September and finishes at the end of April (Mills et al. 1992). C. musculinus has a gestation length of 21 days and each female can produce many pups in her lifetime (six pups per litter; Mills et al. 1992). Females show a high frequency of postpartum oestrus, which implies that a new pregnancy may overlap with the lactation of the previously produced litter (de Villafañe and Bonaventura 1987). Juveniles of C. musculinus reach sexual maturity at around 35 days of age with a mean weight close to $16.5 \mathrm{~g}$ (Sommaro et al. 2009).

\section{Experimental procedures and behavioural testing}

In September 2004, we collected C. musculinus adults in road borders from an area located $30 \mathrm{~km}$ away from the study location and mated them in the Ecology Population Researching Laboratory inside opaque polycarbonate reproductive cages $(29 \times 18 \times 18 \mathrm{~cm})$. Both sex and birth date of offspring were recorded. Individuals were maintained at $21^{\circ} \mathrm{C}$ on a $14: 10$ hours light:dark cycle (lights on at $06: 30$ hours). Rodent Purina laboratory chow and water were available ad libitum. Dry wood shaving was provided for bedding.

In order to control density and manipulate sex ratio of the enclosure populations, we choose 16 families, from 36 couples that bred successfully in the laboratory, taking into account the litter size and the offspring sex ratio. After offspring were weaned (20 days old), eight families were carried to the male-biased enclosures (experimentals), and eight to the unbiased enclosures (controls). In the malebiased enclosures, mothers were removed, meanwhile in the unbiased enclosures both parents remained with their offspring. The initial conditions of each enclosure at the end of November 2004 are shown in Table 1. Before mice were taken to the enclosures, they were weighed and eartagged for permanent identification, and kinship was registered.

In each enclosure, there was a capture-mark-recapture (CMR) grid of $6 \times 10$ traps with an interstation interval of $6 \mathrm{~m}$. One Sherman live trap was placed at each station and baited with a mixture of peanut butter and cow fat. Two trapping sessions of 9 successive days (December 2004) were carried out in each enclosure. First trapping session started after a settlement period of 12 days, and the time interval between trapping sessions was 9 days. Traps were checked each morning, trapped animals were weighed, and reproductive state was recorded. Reproductive condition was judged on the basis of external characters. Males were classified as nonbreeding (abdominal testes) and breeding
Table 1 Demographic initial conditions (end of November 2004) of Calomys musculinus in unbiased and male-biased enclosures located in Espinal Reservation in the National University of Río Cuarto Campus, Argentina

\begin{tabular}{llllll}
\hline & \multicolumn{2}{l}{ Unbiased enclosures } & & \multicolumn{2}{l}{ Male-biased enclosures } \\
\cline { 2 - 3 } \cline { 5 - 6 } & $\mathrm{C}^{\mathrm{a}} \mathrm{I}$ & $\mathrm{C}^{\mathrm{a}} \mathrm{II}$ & & $\mathrm{E}^{\mathrm{b}} \mathrm{I}$ & $\mathrm{E}^{\mathrm{b}} \mathrm{II}$ \\
\hline Families & 4 & 4 & & 4 & 4 \\
Fathers & 4 & 4 & & 4 & 4 \\
Mothers & 4 & 4 & & 0 & 0 \\
Sons & 12 & 12 & & 18 & 19 \\
Daughters & 12 & 12 & & 8 & 8 \\
Sex ratio & 1 & 1 & & 2.75 & 2.87 \\
\hline
\end{tabular}

${ }^{\mathrm{a}}$ Control enclosures; ${ }^{\mathrm{b}}$ Experimental enclosures

(scrotal testes). Females were classified as nonbreeding (imperforate vagina) and breeding (perforate vagina, evidence of pregnancy or suckling). Trap location of each capture was also registered. Since encounters have to be done in the home range of one of the opponents, the home range configuration and size must be known. To estimate individual home range configuration, all captures were plotted on graph paper for each trapping session, and the boundary-strip method (Stickel 1954) was applied.

We conducted dyadic encounters between nonneighbouring reproductively active males of similar weight and age which belonged to different families and established home ranges in the same enclosure at the same trapping session. For each inter-male encounter, we distinguished two animal conditions: home range owner (owner of the home range in which the encounter was performed) and home range intruder (intruder in the home range in which the encounter was made). Animal condition was randomly assigned before each encounter. Owing to the fact that the spatial location of each individual home range was known, the observer was able to recognize the opponent's status. In this study, animals were used only once. Encounters were carried out during the last 2 days of each trapping session to ensure the necessary number of captures (7-8) to estimate the home range configuration. Encounters were conducted between 2 and 6 p.m. in a movable polycarbonate circular opaque arena (COA) of $60-\mathrm{cm}$ height, $210-\mathrm{cm}$ perimeter and $70-\mathrm{cm}$ diameter, by a single observer situated $1 \mathrm{~m}$ away from the arena. This circular arena testing has an open ground area that allows us to test animal behavioural responses on the natural substrate of the home range owner. Before the encounter, one of the opponents was marked on its forehead with a yellow watercolour highlighter for visual identification. Each encounter started with the simultaneous release of both the owner and the intruder into the arena, one on each side of a removable opaque partition. After a 1-min acclimation period, the separator was removed. 
Following Petersen and Helland (1978) and Cutrera et al. (1988), the different types of behaviours were classified as interactive (those behaviours performed with, from or towards the partner) and noninteractive (those behaviours performed individually, not being directed to the opponent). Interactive behaviours observed in C. musculinus during encounters are defined as follows: Side Display ( $\mathrm{Sd}$ approaching the opponent in a sideway stance, often combined with pilo-erection, accompanied by intentional movements of boxing and biting; Attack (At) — rushing and leaping to the opponent with kicks and bites; Pursuit (P) running after the opponent attempting to bite and chase it; Quiet (Q) - individual remains quiet in one place in attitude of alertness, ears down, bending its neck laterally, offering the concave side to the partner and in visual contact with its opponent; Escape (Es) - this behaviour, which is exhibited in response to a pursuit, is a rapid locomotion directed away from the opponent, generally accompanied by squeaks; Lying on the back (Lb)-lying still on the back in a rigid way, ears down, eyes closed or nearly closed; Sniffing partner (Sp) - both individuals stand face to face in close contact, while sniffing the oral region of the opponent; and Sharing space (Ss) - opponents stay close by and share a common space within the COA.Noninteractive behaviours observed in C. musculinus in dyadic encounters are defined as follows: Exploratory behaviour (Ex) - vertical and horizontal environment exploration, individual exploratory movements in all directions along the ground or climbing the lateral fence of the COA; Immobility (I) - the animal lies down or stands motionless except for occasional chewing movements, ignoring the other animal.

Following Wolff et al. (1983), Wolff and Cicirello (1991), Courtalon et al. (2003) and Steinmann et al. (2009), each encounter lasted $5 \mathrm{~min}$ subdivided into 1min intervals. We calculated the rate of each behaviour per encounter and for each opponent as: number of time intervals in which the behaviour was observed at least once on each opponent/total number of time intervals (5). We expressed the rate of each behaviour as a percentage. Following Altmann (1974), we considered behaviours as events not as states. Focal animal sampling (Altmann 1974) was used to record the behaviours. After each encounter ended, animals were released in their own home ranges and the circular arena was cleaned with water.

The research on live animals was performed in a humane manner according to the current Argentinean Laws (National Law 14346).

\section{Statistical analyses}

For statistical analyses, we grouped the rates of the different types of interactive behaviours per encounter in three categories: aggressive behaviours (Sd, At, P), submissive behaviours (Q, Es, Lb) and amicable behaviours ( $\mathrm{Sp}, \mathrm{Ss})$. Noninteractive behaviours (Ex, I) composed a fourth category. Although the dyadic encounters were conducted during two trapping sessions, we assumed a negligible temporal effect since the censuses were separated by a short time interval (9 days; Steinmann et al. 2009). The rates of all behavioural categories (aggressive, submissive, amicable and noninteractive) were tested by treatment (unbiased and malebiased) using Mann-Whitney $U$ tests. These analyses were developed for owners and intruders separately. On the other hand, Mann-Whitney $U$ tests were used to analyse if aggressive behaviour depends on ownership condition. These analyses were developed for unbiased and malebiased enclosures separately.

\section{Results}

During December 2004, a total of 1,029 captures were recorded in 3,840 trap nights, and population size of $C$. musculinus in each enclosure was about 130 mice/ha. Thus, population sizes in the enclosures were similar to those observed in wild populations during the core of the breeding season (Mills et al. 1992).

During this study, both males and females were reproductively active. Thus, we assumed that both females and males performed behaviours associated with breeding. During the study, 114 home ranges of reproductively active C. musculinus were estimated: 62 in unbiased enclosures ( 32 and 30 male and female home ranges, respectively), and 50 in male-biased (36 and 14 male and female home ranges, respectively). Thus, the number of estimated male and female home ranges in unbiased enclosures was similar, whereas in male-biased enclosures, female home ranges represented only $28 \%$ of the estimated home ranges. Males overlapped their home ranges with three or four females in both unbiased and male-biased enclosures. In unbiased enclosures males overlapped their home ranges with three or four males, but in male-biased enclosures, inter-male overlap was absent or only occurred between two males and it did not exceed $10 \%$ of overlapping.

Previously, to the analyses by treatment, Mann-Whitney $U$ tests were used to analyse whether aggressive, submissive, amicable and noninteractive behavioural rates varied between unbiased (control I and II) and male-biased (experimental I and II) enclosures. These analyses were developed for owners and intruders separately. The rate of aggressive, amicable and noninteractive behaviours did not vary between home range owners (aggressive: $U=32.500$, $n=16, p=0.7363$; amicable: $U=35.500, n=16, p=0.9616$; 
noninteractive: $U=33.000, n=16, p=0.7728)$ and intruders (aggressive: $U=28.000, n=16, p=0.4414$; amicable: $U=$ $32.000, n=16, p=0.7003$; noninteractive: $U=24.000, n=16$, $p=0.2482$ ) of either unbiased I and II enclosures. In unbiased enclosures, submissive behaviour was never observed.

The rate of aggressive, submissive and noninteractive behaviours did not vary between owners (aggressive: $U=31.500, n=18, p=0.4268$; submissive: $U=40.500$, $n=18, \quad p=0.9999$; noninteractive: $U=34.500, n=18$, $p=0.5962$ ) and intruders (aggressive: $U=36.000, n=18$, $p=0.6911$; submissive: $U=40.500, n=18, p=0.9999$; noninteractive: $U=37.000, n=18, p=0.7573$ ) of either male-biased I and II enclosures. In male-biased enclosures, amicable behaviour was never observed.

Because no significant differences in the behaviours of owners and intruders were found between unbiased I and II enclosures and between male-biased I and II enclosures, data from both control and from both experimental enclosures were pooled. Aggressiveness, submissiveness and amicableness of males varied in relation to treatment (Table 2). Both male owners and intruders were more aggressive in male-biased than in unbiased enclosures (Fig. 1a, b). Submissive behaviour varied significantly between treatments in intruder males (Table 2), and this behaviour reached values of $20 \%$ in male-biased enclosures (Fig. 1b). Both owners and intruders never exhibited amicable behaviour in male-biased enclosures, but this behaviour reached values of $20 \%$ in unbiased enclosures (Fig. 1a, b). In relation to noninteractive behaviour, it was significantly higher in unbiased than in male-biased enclosures (Fig. 1a, b).

Although males were always more aggressive in malebiased enclosures than in unbiased enclosures, when aggressive behaviour was compared between animal conditions (owner vs. intruder), we found significant differences in malebiased enclosures $(U=7.000, n=36, p=0.000)$. In these enclosures, owners showed a greater rate of aggressive behaviour than intruders. On the other hand, the rate of aggressive behaviour did not vary between owners and intruders in unbiased enclosures $(U=136, n=34, p=0.7697$; (Fig. 2).

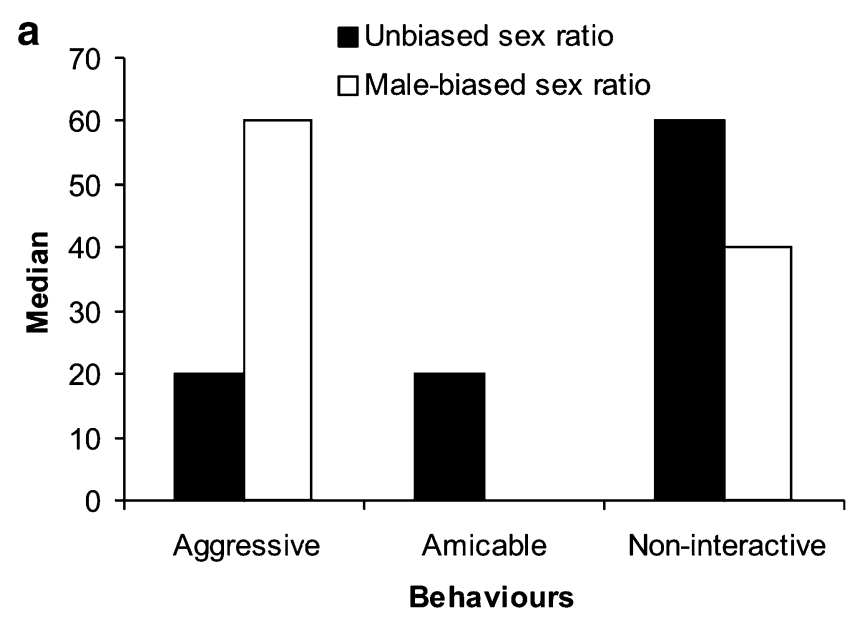

b

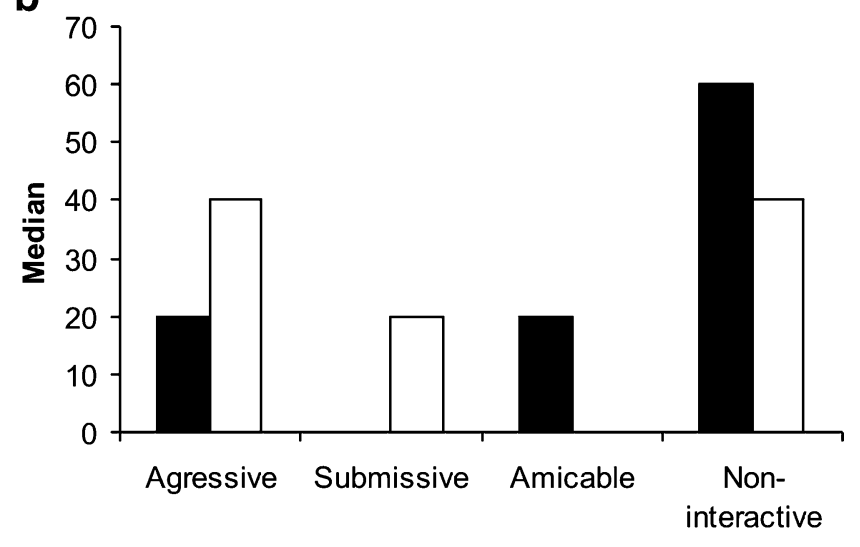

Behaviours

Fig. 1 Medians of aggressive, submissive, amicable and noninteractive behaviours exhibited in the inter-male Calomys musculinus encounters in unbiased and male-biased enclosures by: a owners and b intruders of the home ranges

\section{Discussion}

Within a species, the spacing behaviour of an individual is influenced by the presence or absence of other individuals, and the distribution of resources that may limit fitness (Emlen and Oring 1977; Frank and Heske 1992; Pusenius and Viitala 1993). Several studies showed that male voles and mice avoid each other at both high densities of males and high total population densities (Bond and Wolff 1999; Fortier and Tamarin 1998; Ims 1987; Ostfeld 1985, 1990; Wolff et al.
Table 2 Results of one-tailed Mann-Whitney $U$ tests of aggressive (side display, attack, pursuit), submissive (quiet, escape, lying on the back), amicable (sniffing partner, sharing space) and non-interactive behaviours (exploratory behaviour, immobility) of owner and intruder Calomys musculinus individuals by treatment (sex ratio)

\begin{tabular}{|c|c|c|c|c|c|c|c|c|c|c|c|c|}
\hline & \multicolumn{3}{|c|}{ Aggressive } & \multicolumn{3}{|c|}{ Submissive } & \multicolumn{3}{|c|}{ Amicable } & \multicolumn{3}{|c|}{ Non-interactive } \\
\hline & $U$ & $n$ & $p$ & $U$ & $n$ & $p$ & $U$ & $n$ & $p$ & $U$ & $n$ & $P$ \\
\hline Owner control vs. owner experimental & 0 & 35 & 0.000 & 119 & 35 & 0.262 & 18 & 35 & 0.000 & 0 & 35 & 0.000 \\
\hline Intruder control vs. intruder experimental & 0 & 35 & 0.000 & 34 & 35 & 0.000 & 9 & 35 & 0.000 & 28 & 35 & 0.000 \\
\hline
\end{tabular}




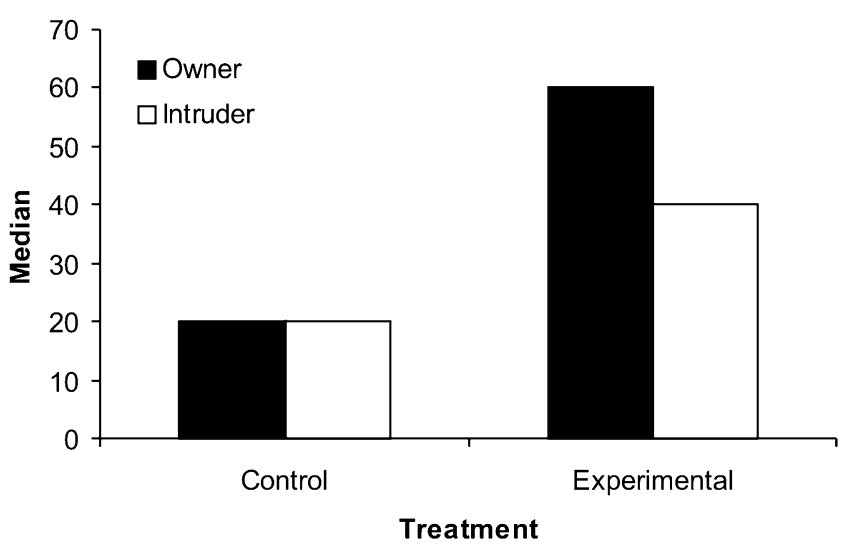

Fig. 2 Medians of aggressive behaviour exhibited in the inter-male Calomys musculinus encounters in relation to treatment and home range owner or intruder condition

1994; Wolff and Schauber 1996). Besides, other behavioural studies found evidence that males are most likely to be aggressive at low densities of females (Flowerdew 1974; Krebs et al. 1969; Krebs 1978; Moorhouse and Macdonald 2008; Nevo 2007). Anderson (1994) established that low availability of females could lead to male competition for mates, usually through direct aggressive interactions. This research provides the first inter-male aggressive behaviour documentation in seminatural populations of $C$. musculinus in which sex ratio was manipulated. We found that males exhibit more intrasexual aggression in male-biased populations than in unbiased populations.

In this study, we found that males exhibited amicable behaviour, high levels of noninteractive behaviours and low levels of aggressive behaviour in unbiased enclosures, as it was previously observed in C. musculinus unbiased sex ratio populations (Steinmann et al. 2009). In relation to noninteractive behaviour, C. musculinus males spent most of the time exploring the environment, suggesting tolerant or peaceful coexistence. However, in male-biased populations, amicable behaviour was absent and males showed high levels of intrasexual aggression. In these conditions, home range owner's aggressiveness would lead to the exclusion of the intruder male from the home range. This spatial dominance is supported by the greater rates of submissive behaviour exhibited by home range intruders in male-biased enclosures. Thus, low density of females would lead to territorial aggression in C. musculinus males. This would suggest that a low availability of breeding females may lead to transient territoriality in C. musculinus males that may act as a strategy to monopolize females and thereby gain increased fitness. Ostfeld (1985), Batzli and Henttonen (1993), Schradin (2004), Loughran (2007) and Moorhouse and Macdonald (2008) found changing patterns of territoriality and intrasexual aggression in males associated with changing density of reproductively active females; males become territorial against other males when females are a slender resource and the inter-male aggressive encounters occur inside their territory boundaries. Many studies have related aggressiveness to spacing and competition (Anderson 1994; Boonstra et al. 1994; Ims 1987; Moorhouse and MacDonald 2005, 2008; Spritzer et al. 2004, 2006). Bond and Wolff (1999) found that male aggression plays a main role in limiting space use; males may adjust their home range sizes to minimize aggressive interactions. Steinmann et al. (2006b) found that the size and the inter-male home range overlap were lower in populations where sex ratios were male-biased than in unbiased populations. Because the degree of home range overlap of C. musculinus males is a consequence of their home range size (Steinmann et al. 2005), the lower overlap degree would indicate a minor movement rate of males in populations with shortage of female resource to avoid encounter among males (Steinmann et al. 2006b). The low degree of inter-male overlap and the minor number of males which overlap their home range registered in this study would be a consequence of inter-male territorial aggression. Thus, according to our results mating with multiple females would have a high cost in male-biased condition because the trespassing boundary home range of another breeding male would become a risk for males.

Rodents territorial behaviour should be modulated by several mechanisms as relatedness (Dewsbury 1988; Ferkin 1990; Sera and Gaines 1994), familiarity (Ferkin 1988; Randall 1989; Randall et al. 2002; Rossell et al. 2008; Vestal and Hellack 1978), ownership status and asymmetry value of the territory (Bester-Meredith and Marler 2007; Gray et al. 2002). The latter mechanism proposed that since territory owners value their territory more than intruders do, they are willing to incur the cost to defend it against intruders (Krebs 1982; Maynard Smith and Parker 1976). In male rodents, the experience with such familiar area would lead to a major spacing ability of home range owners in relation to food (Gray et al. 2002; Schradin 2004), refuge (Schradin and Pillay 2004), and mating resources acquisition (Koskela et al 1997; Ostfeld 1985, Steinmann 2006), enhancing owner fitness in that space. In this study, we found that in male-biased populations, male home range owners were more aggressive than intruders. As our study design allowed us to discard any behavioural differences related with neighbourhood or kinship, the greater aggressiveness observed in male residents would be due to their local knowledge and greater investment in the area. Since neither food nor shelter is a critical resource in the enclosures, male home range owners would have an advantage over intruders in gaining access to receptive females.

In conclusion, female corn mouse density and male ownership status seem to have a large influence on the 
resulting inter-male aggression. This study, together with others (Agrell et al. 1996; Ims 1988; Lambin and Krebs 1991; Lambin 1997; Madison and McShea 1987; Pusenius and Viitala 1993; Steinmann et al. 2006a, b, 2009; Wolff and Cicirello 1990; Ylönen et al. 1988), demonstrates that small rodents have very flexible spacing behaviour that acts as a conditional system adapted to the current environmental conditions. Although our results support the hypothesis that inter-male aggressiveness is in relation to female availability, our data also do not rule out the hypothesis that inter-male aggression depends on male density. Thus, a new study to test if access to females or competition with males has the greatest influence on inter-males aggression (Bond and Wolff 1999; Fortier and Tamarin 1998; Wolff and Schauber 1996) will be of great interest.

Acknowledgements We thank Susana Vilor and Susana Ferrero for their help with the English version of this manuscript and with the statistical data, respectively. This research was made possible by grants of the Consejo Nacional de Investigación Científica y Tecnológica (CONICET) and Secretaría de Ciencia y Técnica (SECyT), Universidad Nacional de Río Cuarto. We also acknowledge anonymous reviewers that provided valuable comments and suggestions that helped us improve the quality of this manuscript.

\section{References}

Agrell J, Erlinge J, Nelson J, Sandell M (1996) Shifting spacing behaviour of male field voles, Microtus agrestis, over the reproductive season. Ann Zool Fenn 33:243-248

Altmann J (1974) Observational study of behavior: sampling methods. Behaviour 49:227-267. doi:10.1163/156853974X00534

Anderson M (1994) Sexual selection. Princeton University Press, Princeton, NJ

Batzli G, Henttonen H (1993) Home range and social organization of the singing vole (Microtus miurus). J Mammal 74:868-878. doi: $10.2307 / 1382425$

Beletsky LD, Orians GH (1987) Territoriality among male red-winged blackbirds: I. Site fidelity and movement patterns. Behav Ecol Sociobiol 20:21-34. doi:10.1007/BF00292163

Beletsky LD, Orians GH (1989) Territoriality among male red-winged blackbirds: III. Testing hypotheses of territorial dominance. Behav Ecol Sociobiol 24:333-339. doi:10.1007/BF00290910

Bester-Meredith JK, Marler CA (2007) Social Experience during development and female offspring aggression in Peromyscus mice. Ethology 113:889-900. doi:10.1111/j.1439-0310.2007.01393.x

Bond ML, Wolff JO (1999) Does access to females or competition among males limit male home-ranges in a promiscuous rodent? J Mammal 80:1243-1250. doi:10.2307/1383174

Bondrup-Nielsen S (1986) Investigation of spacing behaviour of Clethrionomys gapperi by experimentation. J Anim Ecol 55:269279. doi: $10.2307 / 4707$

Boonstra R, Hochachka M, Pavone L (1994) Heterozygosity, aggression, and population fluctuations in meadow voles (Microtus pennsylvanicus). Evolution 48:1350-1363. doi:10.2307/ 2410391

Busch M, Miño MH, Dadon JR, Hodara K (2000) Habitat selection by Calomys musculinus (Muridae, Sigmodontinae) in crop areas of the Pampean region, Argentina. Ecol Austral $10: 15-26$
Cabrera A (1953) Esquema fitogeográfico de la República Argentina. Rev Mus Plata (Botánica) 8:87-168 [In Spanish]

Courtalon P, Dolcemascolo A, Troyano V, Álvarez M, Busch M (2003) Inter and intraspecific relationships in Akodon azarae and Calomys laucha (Rodentia, Sigmodontinae) in Pampean agroecosystems. Mastozool Neotrop 10:27-39

Cutrera RA, Yunes RMF, Castro-Vázquez A (1988) Postpartum sexual behavior of the corn mouse (Calomys musculinus): repertoire, measurements, and effects of removal of pups. J Comp Psychol 102:83-89. doi:10.1037/0735-7036.102.1.83

Davies NB (1981) Calling as an ownership convention on pied wagtail territories. Anim Behav 29:529-534. doi:10.1016/S00033472(81)80115-7

Davies NB, Houston AI (1981) Owners and satellites: the economics of territory defence in the pied wagtail, Motacilla alba. J Anim Ecol 50:157-180. doi:10.2307/4038

de Villafañe G, Bonaventura SM (1987) Ecological studies in crop fields of the endemic area of Argentine hemorrhagic fever. Calomys musculinus movements in relation to habitat and abundance. Mammalia 51:233-248. doi:10.1515/ mamm.1987.51.2.233

Dewsbury DA (1988) Kinship, familiarity, aggression, and dominance in deer mice (Peromyscus maniculatus) in seminatural enclosures. J Comp Psychol 102:124-128. doi:10.1037/0735-7036.102.2.124

Emlen ST, Oring LW (1977) Ecology, sexual selection, and the evolution of mating systems. Science 197:215-223. doi:10.1126/ science. 327542

Ferkin MH (1988) The effect of familiarity on social interactions in meadow voles, Microtus pennsylvanicus: a laboratory and field study. Anim Behav 36:1816-1822. doi:10.1016/S0003-3472(88) 80121-0

Ferkin MH (1990) Kin recognition and social behaviour in microtine rodents. In: Tamarin RH, Ostfeld RS, Pugh SR, Bujalska G (eds) Social systems and population cycles in voles. Birkhauser Verlag, Boston, MA, pp 11-24

Flowerdew JR (1974) Field and laboratory experiments on the social behaviour and populations dynamics of the wood mouse (Apodemus sylvaticus). Ecology 43:499-511

Fortier GM, Tamarin RH (1998) Movement of meadow voles in response to food and density manipulations: a test of the fooddefense and pup-defense hypotheses. J Mammal 79:337-345. doi: $10.2307 / 1382870$

Frank DH, Heske EJ (1992) Seasonal changes in space use patterns in the southern grasshopper mouse, Onychomys torridus torridus. J Mammal 73:292-298. doi:10.2307/1382059

Gray SJ, Jensen SP, Hurst JL (2002) Effects of resource distribution on activity and territory defence in house mice, Mus domesticus. Anim Behav 63:531-539. doi:10.1006/anbe.2001.1932

Hatchwell BJ, Davies NB (1992) An experimental study of mating competition in monogamous and polyandrous dunnocks. Prunella modularis: II. Influence of removal and replacement experiments on mating systems. Anim Behav 43:611-622. doi:10.1016/S0003-3472(05)81020-6

Ims RA (1987) Male spacing system in microtine rodents. Am Nat 130:475-484. doi: $10.1086 / 284725$

Ims RA (1988) Spatial clumping of sexually receptive females induces space sharing among male voles. Nature 335:541-543. doi: $10.1038 / 335541 \mathrm{a} 0$

Knell RJ (2009) Population density and the evolution of male aggression. J Zool 278:83-90. doi:10.1111/j.14697998.2009.00566.x

Koskela E, Mappes T, Ylönen H (1997) Territorial behaviour and reproductive success of bank vole Cletherionomys glarelous females. J Anim Ecol 66:341-349. doi:10.2307/5980

Krebs CJ (1978) A review of the Chitty hypothesis of population regulation. Can J Zool 56:2463-2480. doi:10.1139/z78-335 
Krebs JR (1982) Territorial defence in the great tit Parus major: do residents always win? Behav Ecol Sociobiol 11:185-194. doi:10.1007/BF00300061

Krebs CJ, Keller B, Tamarin R (1969) Microtus population biology: demographic changes in fluctuating populations of $M$. ochrogaster and M. pennsylvanicus in southern Indiana. Ecology 50:587-607. doi:10.2307/1936248

Lambin X (1997) Home range shifts by breeding female Townsend's voles (Microtus townsendii): a test of the territory bequeathal hypothesis. Behav Ecol Sociobiol 40:363-372. doi:10.1007/ s002650050352

Lambin X, Krebs CJ (1991) Spatial organization and mating system of Microtus townsendii. Behav Ecol Sociobiol 28:353-363. doi:10.1007/BF00164385

Loughran MFE (2007) Social organization of the male field vole (Microtus agrestis): a case of transient territoriality? Ann Zool Fenn 44:97-106

Madison DM, McShea WJ (1987) Seasonal changes in reproductive tolerance, spacing and social organization in meadow voles: a microtine model. Am Zool 27:899-908

Maynard Smith JM (1979) Game theory and the evolution of behaviour. Proc R Soc London B Biol Sci 205:475-488. doi:10.1098/rspb.1979.0080

Maynard Smith JM, Parker GA (1976) The logic of asymmetric contests. Anim Behav 24:159-175. doi:10.1016/S0003-3472(76) 80110-8

Mills JN, Childs JE (1998) Ecologic studies of rodent reservoirs: their relevance for human health. Emerg Infect Dis 4:529-537. doi:10.3201/eid0404.980403

Mills JN, Ellis BA, Mckee KT, Maiztegui JI, Childs JE (1992) Reproductive characteristics of rodent assemblages in cultivate region of central Argentina. J Mammal 73:515-526. doi:10.2307/ 1382017

Moorhouse TP, Macdonald DW (2005) Temporal patterns of range use in water voles: do females territories drift? J Mammal 86:655661. doi:10.1644/1545-1542(2005)086[0655:TPORUI]2.0.CO;2

Moorhouse TP, Macdonald DW (2008) What limits male range sizes at different population densities? Evidence from three populations of water voles. J Zool 274:395-402. doi:10.1111/j.14697998.2007.00399.x

Nelson J (1995a) Determinants of male spacing behaviour in microtines: an experimental manipulation of female spatial distribution and density. Behav Ecol Sociobiol 37:217-223. doi:10.1007/ BF00177400

Nelson J (1995b) Intrasexual competition and spacing behaviour in males of the field vole, Microtus agrestis, as revealed under constant female density and spatial distribution. Oikos 73:9-14. doi: $10.2307 / 3545719$

Nevo E (2007) Evolution of pacifism and sociality in blind mole-rats. In: Wolff JO, Sherman PW (eds) Rodent societies, an ecological and evolutionary perspective. University of Chicago Press, pp 299-301

Ostfeld RS (1985) Limiting resources and territoriality in microtine rodents. Am Nat 126:1-15. doi:10.1086/284391

Ostfeld RS (1990) The ecology of territoriality in small mammals. Trends Ecol Evol 5:411-415. doi:10.1016/0169-5347(90) 90026-A

Ostfeld RS, Canham CD (1995) Density-dependent processes in meadow voles: an experimental approach. Ecology 76:521-532. doi: $10.2307 / 1941210$

Ostfeld RS, Klosterman LL (1990) Microtine social systems, adaptation, and the comparative method. In: Tamarin RH, Ostfeld RS, Pugh SR, Bujalska G (eds) Social systems and population cycles in voles. Birkhauser Verlag, Basel, Switzerland, pp 35-44
Ostfeld RS, Canham CD, Pugh SR (1993) Intrinsic density-dependent regulation of vole populations. Nature 366:259-261. doi: $10.1038 / 366259 \mathrm{a} 0$

Parker GA, Rubenstein DI (1981) Role assessment, reserve strategy, and acquisition of information in asymmetric animal conflicts. Anim Behav 29:221-240. doi:10.1016/S0003-3472(81)80170-4

Petersen MK, Helland MJ (1978) Behavioral interactions in Sigmodon fulviventer and S. hispidus. J Mammal 59:118-124. doi:10.2307/ 1379881

Pusenius J, Viitala J (1993) Demography and regulation of breeding density in the field vole, Microtus agrestis. Ann Zool Fenn 30:123-130

Randall JA (1989) Territorial-defense interactions with neighbors and strangers in banner-tailed kangaroo rats. J Mammal 70:308-315. doi: $10.2307 / 1381512$

Randall JA, Hekkala ER, Cooper LD, Barfield J (2002) Familiarity and flexible mating strategies of a solitary rodent, Dipodomys ingens. Anim Behav 64:11-21. doi:10.1006/anbe.2002.3029

Rossell F, Gundersen G, Le Galliard J (2008) Territory ownership and familiarity status affect how much male root voles (Microtus oeconomus) invest in territory defence. Behav Ecol Sociobiol 62:1559-1568. doi:10.1007/s00265-008-0585-5

Schradin C (2004) Territorial defense in a group-living solitary forager: who, where, against whom? Behav Ecol Sociobiol 55:439-446. doi:10.1007/s00265-003-0733-x

Schradin C, Pillay N (2004) The striped mouse from succulent karoo of South Africa: a territorial group living solitary forager with communal breeding and helpers at the nest. J Comp Psychol 118:37-47. doi:10.1037/0735-7036.118.1.37

Sera WE, Gaines MS (1994) The effect of relatedness on spacing behaviour and fitness of female prairie voles. Ecology 75:1560 1566. doi: $10.2307 / 1939617$

Shier MD, Randall JA (2004) Spacing as a predictor of social organization in kangaroo rats (Dipodomys heermanii arenae). J Mammal 85:1002-1008. doi:10.1644/107

Sommaro L, Gomez D, Steinmann A, Priotto J (2009) Sexual maduration and reproductive activity of spring-born female corn mice, Calomys musculinus, in absence of adults. Mastozoología Neotropical 16:403-410

Spritzer MD, Solomon NG, Meikle DB (2004) Influence of scramble competition for mates upon the spatial ability of male meadow voles. Anim Behav 69:375-386. doi:10.1016/j.anbe hav.2004.03.015

Spritzer MD, Solomon NG, Meikle DB (2006) Social dominance among male meadow voles is inversely related to reproductive success. Ethology 112:1027-1037. doi:10.1111/j.14390310.2006.01260.x

Stamps J (1995) Motor learning and the value of familiar space. Am Nat 146:41-58. doi:10.1086/285786

Steinmann AR (2006) Comportamiento de espaciamiento de Calomys musculinus (Rodentia: Muridae). PhD thesis. Universidad Nacional de Río Cuarto, Provincia de Córdoba, Argentina

Steinmann AR, Priotto JW, Castillo EA, Polop J (2005) Size and overlap of home range in Calomys musculinus (Muridae: Sigmodontinae). Acta Theriol 50:197-206

Steinmann AR, Priotto J, Sommaro L, Polop J (2006a) Spacing behaviour of juveniles corn mice, Calomys musculinus at the beginning of the breeding period, in absence of adult males. Acta Oecol 29:305-310. doi:10.1016/j.actao.2005.11.010

Steinmann AR, Priotto J, Sommaro L, Polop J (2006b) The influence of adult female absence on the spacing behaviour of juvenile corn mice, Calomys musculinus: a removal experiment. Ann Zool Fenn 43:366-372 
Steinmann A, Priotto J, Polop J (2009) Territorial behaviour in corn mice, Calomys musculinus (Muridae, Sigmodontinae) with regard to mating system. J Ethol 27:51-58. doi:10.1007/s10164-008-0083-2

Stickel L (1954) A comparison of certain methods of measuring ranges of small mammals. J Mammal 35:1-5. doi:10.2307/1376067

Tobias J (1997) Asymmetric territorial contests in the European robin: the role of settlement costs. Anim Bahav 54:9-21. doi:10.1006/ anbe. 1996.0383

Vestal BM, Hellack JJ (1978) Comparison of neighbor recognition in two species of deer mice (Peromyscus). J Mammal 59:339-346. doi:10.2307/1379918

Wolff JO (1985) Behaviour. In: Tamarin RH (ed) Biology of new world Microtus. Spec Publ Am Soc Mammal 8:340-372

Wolff JO (1993) Why are female small mammals territorial? Oikos 68:364-370. doi: $10.2307 / 3544853$

Wolff JO, Cicirello DM (1990) Mobility versus territoriality: alternative reproductive strategies in white-footed mice. Anim Behav 39:1222-1224. doi:10.1016/S0003-3472(05)80799-7

Wolff JO, Cicirello DM (1991) Comparative paternal and infanticidal behavior of sympatric white-footed mice (Peromyscus leucopus noveboracensis) and deermice ( $P$. maniculatus nubiterrae). Behav Ecol 2:38-45. doi:10.1093/beheco/2.1.38
Wolff JO, Dunlap AS (2002) Multi-male mating, probability of conception, and litter size in the prairie vole (Microtus ochrogaster). Behav Processes 58:105-110. doi:10.1016/S03766357(02)00022-0

Wolff JO, Macdonald DW (2004) Promiscuous females protect their offspring. Trends Ecol Evol 19:127-134. doi:10.1016/j. tree.2003.12.009

Wolff JO, Schauber EM (1996) Space use and juveniles recruitment in gray-tailed voles in response to intruder pressure and food abundance. Acta Theriol 41:35-43

Wolff JO, Freeberg MH, Dueser RD (1983) Interspecific territoriality in two sympatric species of Peromyscus (Rodentia: Cricetidae). Behav Ecol Sociobiol 3:397-427

Wolff JO, Edge WD, Bentley DR (1994) Reproductive and behavioural biology of the gray-tailed vole. J Mammal 75:873-879. doi: $10.2307 / 1382469$

Ylönen H, Viitala J (1985) Social organization of an enclosed winter population of the bank vole Clethrionomys glareolus. Ann Zool Fenn 22:353-358

Ylönen H, Kojola T, Viitala J (1988) Changing female spacing behaviour and demography in an enclosed population of Clethrionomys glareolus. Hol Ecol 11:354-363 